\title{
Patient-reported outcome 2 years after lung transplantation: does the underlying diagnosis matter?
}

This article was published in the following Dove Press journal:

Patient Related Outcome Measures

17 November 2012

Number of times this article has been viewed

\author{
Maria Jose Santana' \\ David Feeny ${ }^{2}$ \\ Sunita Ghosh ${ }^{3}$ \\ Dale C Lien ${ }^{4}$ \\ 'Faculty of Medicine, University \\ of Calgary, Calgary, Alberta, Canada; \\ ${ }^{2}$ Kaiser Permanente Center \\ for Health Research, Portland, \\ OR, USA; ${ }^{3}$ Cross Cancer Center, \\ University of Alberta, Edmonton, \\ Alberta, Canada; ${ }^{4}$ University of \\ Alberta Hospital, Edmonton, Alberta, \\ Canada
}

Purpose: Transplantation has the potential to produce profound effects on survival and healthrelated quality of life (HRQL). The inclusion of the patient's perspective may play an important role in the assessment of the effectiveness of lung transplantation. Patient perspectives are assessed by patient-reported outcome measures, including HRQL measures. We describe how patients' HRQL among different diagnosis groups can be used by clinicians to monitor and evaluate the outcomes associated with transplantation.

Methods: Consecutive lung transplant recipients attending the lung transplant outpatient clinic in a tertiary institution completed the 15-item Health Utilities Index (HUI) questionnaire on a touchscreen computer. The results were available to clinicians at every patient visit The HUI3 covers a range of severity and comorbidities in eight dimensions of health status. Overall HUI3 scores are on a scale in which dead $=0.00$ and perfect health $=1.00$; disability categories range from no disability $=1$ to severe disability $<0.70$. Single-attribute and overall HUI3 scores were used to compare patients' HRQL among different diagnosis groups. Randomeffect models with time since transplant as a random variable and age, gender, underlying diagnoses, infections, and broncholitis obliterans syndrome as fixed variables were built to identify determinants of health status at 2-years posttransplantation.

Results: Two hundred and fourteen lung transplant recipients of whom $61 \%$ were male with a mean age of 52 (19-75) years were included in the study. Chronic obstructive pulmonary disease and cystic fibrosis patients displayed moderate disability, while pulmonary fibrosis and pulmonary arterial hypertension patients displayed severe disability. Patients with chronic obstructive pulmonary disease had the worst pain level, whereas patients with pulmonary fibrosis had the worst emotion and cognition levels. A random-effect model confirmed that development of broncholitis obliterans syndrome was the most important determinant of health status $(P=0.03)$ compared to other variables, such as cytomegalovirus infections and underlying diagnoses.

Conclusion: Descriptions of patients' HRQL among different diagnosis groups could be used by clinicians to assist individualized patient care.

Keywords: patient-reported outcomes, health-related quality of life measures, underlying diagnoses in lung transplant recipients, health utilities index

\section{Introduction}

Traditionally, the assessment of outcomes in lung transplantation has focused on patient survival. Lung transplantation has lower long-term survival compared with many other solid-organ transplants. ${ }^{1}$ Graft failure, chronic rejection, or broncholitis obliterans syndrome (BOS) and infections, such as cytomegalovirus (CMV), are common causes of death. ${ }^{1}$ 
The inclusion of the patients' perspective is recognized as an important step in the assessment of the effectiveness of lung transplantation. Lung transplantation appears to improve pulmonary function, 6-minute walk test results, and oxygenation. Patients' perspectives are assessed by patientreported outcome (PROs) measures, including health-related quality of life (HRQL) measures. PROs evaluate the impact of treatment on patient functioning and on patient physical and emotional status and overall well-being. The inclusion of PROs allows health care providers to gather information that is important for patients and that goes beyond the biomedical and survival models. Furthermore, the addition of patient perspectives allows health care providers to assist in the decision-making processes for individual patients and clinical policy.

The lung transplant team at a tertiary institution has recognized the importance of including PROs into the routine clinical care of lung transplant patients. The Health Utilities Index (HUI) has been incorporated into the routine clinical care of lung transplant patients since July 2005 to monitor and evaluate the outcomes associated with transplantation as well as to assist individualized patient care.

The HUI is useful because it describes a great number of health states and captures the severity of the disease and burden of side effects associated with drugs and other treatments along with the burdens associated with comorbidities.

We assessed whether PROs measured by HRQL measures at 2 years of lung transplantation provide a description of patients' HRQL among different diagnosis groups; did the underlying diagnoses matter? For instance, did patients with cystic fibrosis report the same outcomes as patients with chronic obstructive pulmonary disease (COPD)? Furthermore, we assessed the determinants of health and postulated that at 2 years posttransplantation the health status and HRQL of survivors would be associated with age, sex, diagnosis, and complications, including BOS and CMV infection.

\section{Methods}

\section{Patients and process}

Consecutive lung transplant recipients attending the lung transplant out-patient clinic at the University of Alberta Hospital completed the 15-item HUI questionnaire on a touch-screen computer with every visit starting in July 2005. This is routinely conducted as part of the lung transplant program. Although the collection of HRQL data is prospective, in this paper we present cross-sectional data at 2 years posttransplantation. Patients were excluded if younger than 18 years old, if hospitalized at the time of study initiation, or if unable to complete questionnaires in English. Written information about the study was provided to patients before obtaining informed consent. Once the patient consented to participate in the study, she or he completed the baseline measures. Ethics approval was obtained from the Health Research Ethics Panel B, University of Alberta, Canada.

Patients were asked to complete the HUI questionnaire on a touch-screen computer upon arrival at the out-patient clinic. The advantages of the use of a touch-screen computer over a paper-and-pencil questionnaire are it allows the collection of electronic data that can be stored and scored automatically and it facilitates the timely availability of the results for presentation to clinicians at each patient's visit in "real time." "

\section{Measures}

HRQL: Health Utilities Index Mark 3 (HUI3). The 15-item, HUI self-assessment, self-complete,1-week recall questionnaire ${ }^{3}$ was used in this study. The HUIs are multiattribute preferencebased measures that are easy to administer, score, and interpret. The HUI3 ${ }^{3-5}$ includes eight attributes (vision, hearing, speech, ambulation, dexterity, cognition, emotion, and pain and discomfort) with five or six levels for each attribute. HUI3 ${ }^{4}$ single-attribute utility scores (SAUS) are on a scale in which the score for the most highly impaired level is 0.00 and the score for normal is 1.00 . HUI3 overall scores are on a scale in which the all-worst HUI3 state has a score of -0.36 , dead is 0.00 , and perfect health is $1.000^{3,4}$ disability categories range from no disability $=1$ to severe disability $<0.70 ., 3$ Changes of 0.03 or more in overall HUI scores and 0.05 or more in single-attribute scores are clearly clinically important. ${ }^{5}$

Posttransplant patients receiving immunosuppressant drugs may suffer vision and speech problems, depression, and cognitive deficits. Also, changes in emotional states due to some treatments may be present in some patients and captured by HUI3 emotion. Symptoms, such as fatigue, pain, and breathing limitations, will limit ambulation and health status.

\section{Patient's sociodemographic and clinical characteristics}

At the first study visit (baseline assessment), the patients completed a brief sociodemographic questionnaire. Items included age, sex, level of education, employment status, and a list of comorbidities developed by the transplant specialists. 
Clinical data were obtained from chart review, including type of transplant, time since transplant, current drug therapy, pulmonary function test results, and 6-minute walk test.

\section{Determinants of health variables}

In lung transplant recipients, BOS is the major cause of mortality and morbidity. ${ }^{1}$ Struder et $\mathrm{al}^{6}$ assessed mortality causes at different time frameworks from 0 days to 5 years posttransplantation. Between 1 and 3 years, the major cause of mortality was BOS. We follow the International Society of Heart and Lung Transplantation ${ }^{7}$ and define BOS as a sustained and significant decline in forced expiratory volume in 1 second $\left(\mathrm{FEV}_{1}\right)$ of at least $20 \%$ of the predicted baseline value or on the presence of obliterative broncholitis in biopsies, even if the lung function had not deteriorated.

CMV infection is recognized as a common complication in lung transplant patients. ${ }^{1}$ Knowing the impact on your patient population is important in order to design prophylaxis and surveillance strategies.

\section{Data analyses}

Descriptive statistics were performed to summarize patients' HRQL, sociodemographic characteristics, and clinical characteristics and compare patients' health statuses by underlying diagnosis. Random-effect models, with time since transplant as a random variable and age, sex, underlying diagnoses, CMV, and BOS as fixed variables, were built to identify determinants of health status. Deceased patients were added to the model (overall HUI3 =0). Data analyses were conducted using the statistical software packages SPSS version 17.0 (IBM Corporation, Armonk, NY) and SAS version 9.1 (SAS Institute Inc, Cary, NC).

\section{Results \\ Participants}

By September 2010, 287 patients had visited the outpatient clinic, three pre-transplant patients refused to participate, and 284 patients completed the HUI3. Seventy patients were pretransplant and not included in the study. Two hundred and fourteen lung transplant recipients were included. Patients completed an average of three assessments. We present data at 2 years posttransplantation. Out of the 214 patients, $39 \%$ were female with a mean age of $52(19-75)$ years. Table 1 displays the sociodemographic and clinical characteristics of the patients. The mean number of chronic conditions was 1.7 (1.5) from a list of 20 conditions, with osteoporosis being the most common. The majority of the patients received a double lung transplant (81\%), and only a minority $(2 \%)$ received living donor transplants. Table 2 describes the patient cohort stratified by underlying diagnoses. COPD was the most common (39\%) and pulmonary arterial hypertension (PAH) was the least common (4\%) underlying diagnosis. Talcoidosis and sarcoidosis were classified as other (16\%). Eight percent of the deceased patients suffered pulmonary fibrosis (PF).

\section{Health status and HRQL}

Table 3 displays mean overall utility HUI3 scores and single-attribute utility scores for the most affected

Table I Demographic and clinical characteristics

\begin{tabular}{|c|c|}
\hline Mean age (SD) & $52(13.6)$ \\
\hline Sex, \% & 39 \\
\hline \multicolumn{2}{|l|}{ Female } \\
\hline \multicolumn{2}{|l|}{ Race/ethnicity, \% } \\
\hline White & 93 \\
\hline American Indian & 3 \\
\hline East Indian & 2 \\
\hline Asian & 1 \\
\hline Black & I \\
\hline \multicolumn{2}{|l|}{ Marital status, \% } \\
\hline Married & 25 \\
\hline Single & 23 \\
\hline Divorced & 15 \\
\hline Other & 37 \\
\hline \multicolumn{2}{|l|}{ Education, \% } \\
\hline High school & 54 \\
\hline University & 40 \\
\hline Other & 6 \\
\hline \multicolumn{2}{|l|}{ Employment, \% } \\
\hline Working & 18 \\
\hline Unemployed & 13 \\
\hline Retired & 22 \\
\hline Disability & 47 \\
\hline \multicolumn{2}{|l|}{ General health, \% } \\
\hline Excellent & 6 \\
\hline Very good & 38 \\
\hline Good & 38 \\
\hline Fair & 14 \\
\hline Poor & 4 \\
\hline Mean number of comorbidities (SD) & $1.7(1.5)$ \\
\hline \multicolumn{2}{|l|}{ Chronic conditions, \% } \\
\hline Arthritis & 15 \\
\hline Osteoporosis & 33 \\
\hline Hypertension & 31 \\
\hline Diabetes & 18 \\
\hline Other & 3 \\
\hline \multicolumn{2}{|l|}{ Type of transplant } \\
\hline Double & 81 \\
\hline Single & 11 \\
\hline Heart/lung & 6 \\
\hline Living donor & 2 \\
\hline Mean 6-minute walk test, in meters (SD) & $548(155)$ \\
\hline Mean FEV,$\%$ predicted (SD) & $67.10(25.19)$ \\
\hline
\end{tabular}

Note: $\mathrm{n}=214$.

Abbreviations: $\mathrm{FEV}_{1}$, forced expiratory volume in I second; SD, standard deviation. 
Table 2 Distribution of number of patients per underlying diagnoses

\begin{tabular}{llllll}
\hline & COPD & CF & PF & PAH & Other $^{\mathbf{a}}$ \\
\hline $\begin{array}{l}\text { Alive } \\
(\mathrm{n}=174)\end{array}$ & $74(34 \%)$ & $34(16 \%)$ & $32(15 \%)$ & $7(3 \%)$ & $27(13 \%)$ \\
$\begin{array}{l}\text { Deceased } \\
(\mathrm{n}=40)\end{array}$ & $\mathrm{II}(5 \%)$ & $5(2.2 \%)$ & $16(8 \%)$ & $\mathrm{I}(0.5 \%)$ & $7(3.3 \%)$ \\
$\begin{array}{l}\text { Total } \\
(\mathrm{n}=214)\end{array}$ & $85(39 \%)$ & $39(18 \%)$ & $48(23 \%)$ & $8(4 \%)$ & $34(16 \%)$ \\
\hline
\end{tabular}

Note: ${ }^{\mathrm{T} T}$ alcosis and sarcoidosis.

Abbreviations: COPD, chronic obstructive pulmonary disease; CF, cystic fibrosis; $\mathrm{PF}$, pulmonary fibrosis; PAH, pulmonary arterial hypertension.

attributes, ambulation, pain, emotion, and cognition. At 2 years posttransplantation, COPD and cystic fibrosis patients displayed moderate disability (mean overall HUI3 scores of 0.70 and 0.74 , respectively), while PF and PAH patients displayed severe disability (mean overall HUI3 scores of 0.68 and 0.65 , respectively). Patients with PF had the worst emotion and cognition levels.

The percentage of women in the severe category was higher than men (39\% versus 28\%). In general, women were sicker than males (mean overall HUI3 score of 0.67 and 0.75 , respectively). Women had the worst ambulation, emotion, and cognition levels, whereas their pain levels were better than their male counterparts (see Figure 1). Differences in HUI3 scores between females and males were clinically important but not statistically significant.

Within 2 years posttransplant, 65 patients developed BOS but only 16 died (ten women and six men). Table 4 summarizes the random-effect model results and confirms that development of BOS was a determinant of health status $(P=0.03)$. Age and sex, which are typically important determinants of health in more general population samples, are not important determinants of health in a group with important and complex health problems.

The use of HRQL measures in routine clinical care of lung transplant recipients highlighted the health issues for patients who survive to at least 2 years posttransplantation with different underlying diagnoses.

\section{Discussion}

The present study is the first to provide a detailed description of posttransplant patients' burdens by underlying diagnoses at 2 years posttransplantation. We described the differences across groups, identifying those recipients reporting the worst HRQL, such as patients with underlying pulmonary fibrosis. We noted that women reported poorer health than men. Furthermore, we were able to confirm the negative impact of BOS on patient's health status.

During the last decade, numerous studies ${ }^{8-25}$ have reported improvements in HRQL after lung transplantation. We have contributed to the literature by highlighting the areas that need attention within each diagnostic group. Among previous studies, Kugler et al $^{11}$ studied 280 heart-lung and lung recipients, uniquely reporting the association between HRQL and patient characteristics, type of transplant, and diagnosis. The authors found that cystic fibrosis patients, single-lung transplants, and older patients showed significantly lower HRQL. Other studies focused assessment on specific diagnosis. ${ }^{19-22}$ However, our study is the first to provide a detailed description of posttransplant patients' burden by underlying diagnoses at 2 years posttransplantation. This additional information is important because it provides an opportunity for health care providers to tailor care to the underlying diagnosis and characteristics of individual patients. For instance, after lung transplantation, emotional health and pain continue to be negatively affected. ${ }^{8,21}$ Furthermore, Nickels ${ }^{26}$ described the importance of detecting deficits in cognition in lung transplant recipients. Ongoing cognitive deficit may be due to thyroid and other metabolic abnormalities, nutritional deficiencies, and medication side effects. Post-lung transplant patients are taking complex medication regimens; thus preserving cognition to enhance adherence is paramount.

In our sample, women displayed a lower HUI3 overall score. This result confirms previous findings. ${ }^{23-25}$ In both studies, female recipients reported more distress and symptom frequency than male recipients. Lanuza et $\mathrm{al}^{25}$ found that women were concerned about body satisfaction and sexual

Table 3 Mean (SD) HUI3 scores by underlying diagnosis at 2 years posttransplantation

\begin{tabular}{llllll}
\hline Utility score & COPD & CF & PF & PAH & Other $^{\mathrm{a}}$ \\
\hline OUSHUI3 & $0.70(0.22)$ & $0.74(0.19)$ & $0.65(0.25)$ & $0.68(0.17)$ & $0.65(0.28)$ \\
HUI3 ambulation & $0.91(0.17)$ & $0.95(0.10)$ & $0.89(0.09)$ & $0.67(0.32)$ & $0.94(0.10)$ \\
HUI3 emotion & $0.92(0.12)$ & $0.92(0.18)$ & $0.86(0.26)$ & $0.94(0.05)$ & $0.99(0.01)$ \\
HUI3 pain & $0.77(0.27)$ & $0.90(0.10)$ & $0.81(0.18)$ & $0.92(0.00)$ & $0.87(0.09)$ \\
HUI3 cognition & $0.94(0.12)$ & $0.92(0.18)$ & $0.88(0.28)$ & $0.95(0.08)$ & $0.98(0.02)$ \\
\hline
\end{tabular}

Note: ${ }^{\mathrm{a}}$ Talcosis and sarcoidosis.

Abbreviations: SD, standard deviation; OUSHUI3, overall utility score HUI3; COPD, chronic obstructive pulmonary disease; CF, cystic fibrosis; PF, pulmonary fibrosis; $\mathrm{PAH}$, pulmonary arterial hypertension. 


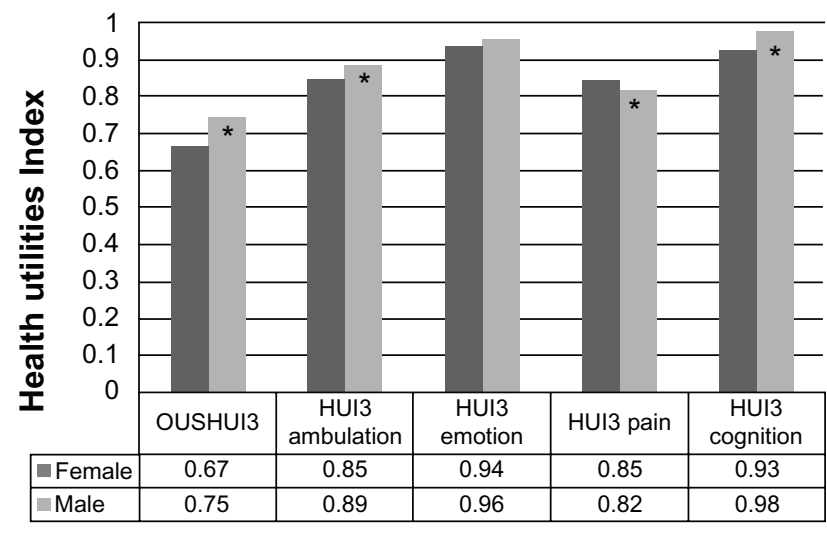

Figure I Mean health utilities index scores by sex.

Note: *Clinically important difference.

Abbreviations: HUI3, health utitlities index mark 3; OUSHUI3, overall utility score HUI3.

functioning after transplantation. Rodrigue and $\mathrm{Baz}^{24}$ noted distress associated with body appearance and appetite changes among female patients. Although Limbos et $\mathrm{al}^{23}$ did not detect any difference, they suggested that after transplantation women may continue to have significant impairments. However, Singer et $\mathrm{a}^{10}$ found that post-lung transplant women enjoyed better health than their male counterparts. The authors used a standard gamble utility measure and attributed their findings to women risk aversion driving their standard gamble score toward higher values. The gap in the association between gender and posttransplant health status will require further research. Most importantly, members of the lung transplant team should consider the sex difference, develop symptom management strategies, and individualize patient care.

Previous studies corroborated the negative impact of BOS on a patient's health status. ${ }^{12-16,27-31}$ These studies reported the relationship between BOS and decreased HRQL in a cross-sectional analysis. The most compelling evidence was provided by van Den Berg et $\mathrm{al}^{27}$ who compared patients with and without BOS. The authors highlighted the association

Table 4 Random effect model

\begin{tabular}{llll}
\hline Parameter & Beta & Standard error & P-value \\
\hline CMV infections & -0.001 & 0.060 & 0.96 \\
Sex & -0.053 & 0.032 & 0.11 \\
Age & -0.001 & 0.002 & 0.65 \\
BOS & -0.07 & 0.03 & 0.03 \\
Diagnosis COPD & 0.001 & 0.05 & 0.98 \\
Diagnosis CF & 0.05 & 0.05 & 0.31 \\
Diagnosis PF & -0.04 & 0.06 & $0.5 \mathrm{I}$ \\
Diagnosis PAH & 0.07 & 0.08 & 0.36 \\
\hline
\end{tabular}

Abbreviations: CMV, cytomegalovirus infections; BOS, broncholitis obliterans syndrome; COPD, chronic obstructive pulmonary disease; CF, cystic fibrosis; PF, pulmonary fibrosis; PAH, pulmonary arterial hypertension. between BOS and reduction in HRQL with a marked decrease in patient mobility. Our findings suggested that after adjusting for age, sex, and underlying diagnoses, BOS continues to be a strong determinant of health.

Our findings illustrate the experiences of recipients of lung transplants and suggest that differences exist among underlying diagnoses groups. The identification of individual patient burdens can be used by clinicians to monitor and evaluate the outcomes associated with lung transplantation. Past studies confirmed the benefit of assessing HRQL in lung transplantation. Anyanwu et al ${ }^{9}$ recommended HRQL collection as part of a standard clinical assessment for research purposes and clinical follow up. Santana et $\mathrm{a}^{32}$ described the effects of HRQL measures in the management of lung transplant patients and advised on routine clinical use. Singer et a ${ }^{10}$ suggested that not only survival but also HRQL data should be included in the mathematical models used to inform lung allocation decisions and the choice of lung transplant operations. Yusen ${ }^{33}$ highlighted the importance of including HRQL measures in assessing the outcomes in lung transplantation. The benefit of using HRQL measures in routine clinical care is supported by organizations such as the International Society of Heart and Lung Transplantation (ISHLT). ISHLT has launched an initiative toward the creation of a common set of HRQL measures to be used internationally. Further support is provided by the International Society of Quality of Life (ISOQOL). ISOQOL has published several peer-reviewed documents on its website (http://www.isoqol.org) to aid the selection and implementation process of HRQL measures.

The results of this study need to be interpreted within the context of its limitations. Our sample included patients attending the outpatient clinic in a tertiary institution excluding hospitalized patients. Hospital setting, patient demographics and clinical characteristics, and clinical management may have impacted the results. Results may not be generalizable to other settings.

\section{Conclusion}

PROs measured by HRQL 2 years after lung transplantation provide a description of patients' HRQL among different diagnosis groups. This description can be used by clinicians to plan individualized patient care. Lung transplant programs should consider routinely collecting HRQL data to complement patient care and quality of care.

\section{Acknowledgments}

We thank the participant patients and the outpatient transplant team for their collaboration in this study. This study was 
funded by the Alberta Hospital Foundation and by Roche Pharmaceuticals.

\section{Disclosure}

Dr David Feeny has a proprietary interest in Health Utilities Incorporated (HUInc), Dundas, Ontario, Canada. HUInc distributes copyrighted HUI materials and provides methodological advice on the use of HUI. The authors report no other conflicts of interest in this work.

\section{References}

1. Orens JB, Garrity ER. General overview of lung transplantation and review of organ allocation. Proc Am Thorac Soc. 2009;6(1):13-19.

2. Velikova G, Wright EP, Smith AB, et al. Automated collection of quality of life data: a comparison of paper and computer touch-screen questionnaires. J Clin Oncol. 1999;17(3):998-1007.

3. Furlong W, Feeny D, Torrance G, Barr R. The Health Utilities Index $\left(\mathrm{HUI}^{\circledR}\right)$ system for assessing health-related quality of life in clinical studies. Ann Med. 2001;33(5):375-384.

4. Feeny D, Furlong W, Torrance G, et al. Multi-attribute and single-attribute utility functions for the Health Utilities Index Mark 3 system. Med Care. 2002;40(2):113-128.

5. Horsman J, Furlong W, Feeny D, Torrance G. The Health Utilities Index $\left(\mathrm{HUI}^{\circledR}\right)$ : concepts, measurement properties and applications. 2003. Available from: http://www.hqol.com/content/1/1/54. Accessed May 2012.

6. Struder SM, Levy RD, McNeil K, Orens JB. Lung transplant outcomes: a review of survival, graft function, physiology, health-related quality of life and cost-effectiveness. Eur Respir J. 2004;24:674-685.

7. Stewart S, Fishbein MC, Snell GI, et al. Revision of the 1996 working formulation for the standardization of nomenclature in the diagnosis of lung rejection. J Heart Lung Transplant. 2007;26:1229-1242.

8. Santana MJ, Feeny D, Jackson K, Weinkauf J, Lien D. Improvement in health-related quality of life after lung transplantation. Can Respir J. 2009;16(5):153-158.

9. Anyanwu AC, McGuire A, Rogers CA, Murday AJ. Assessment of quality of life in lung transplantation using a simple generic tool. Thorax. 2001;56:218-222.

10. Singer L, Gould MK, Tomlinson G, Theodore J. Determinants of health utility in Lung and heart-lung transplant recipients. Am J Transpl. 2005;5:103-109.

11. Kugler C, Fisher S, Gottlieb J, et al. Health-related quality of life in two hundred-eighty lung transplant recipients. J Heart Lung Transpl. 2005;24(12):2262-2268.

12. Gross CR, Savick K, Bolman RM, Hertz MI. Long-term health status and quality of life outcomes of lung transplant recipients. Chest. 1995;108:1587-1593.

13. TenVergert E, Essink-Bot ML, GeertsmaA, van Enckevort PJ, de Boer WJ, van der Bij W. The effect of lung transplantation on health-related quality of life: a longitudin al study. Chest. 1998;113:358-364.

14. Limbos MM, Joyce DP, Chan CK, Kesten S. Psychological functioning and quality of life in lung transplant candidates and recipients. Chest. 2000;118:408-416.

Patient Related Outcome Measures

\section{Publish your work in this journal}

Patient Related Outcome Measures is an international, peer-reviewed, open access journal focusing on treatment outcomes specifically relevant to patients. All aspects of patient care are addressed within the journal and practitioners from all disciplines are invited to submit their work as well as healthcare researchers and patient support groups.
15. Lanuza D, Lefaiver C, Mc Cabe M, Farcas GA, Garrity E Jr. Prospective study of functional status and quality of life before and after lung transplantation. Chest. 2000;118:115-122.

16. Stavern K, Bjørtuft O, Lund MB, Kongshaug K, Geiran O, Boe J. Health-related quality of life in lung transplant candidates and recipients. Respiration. 2000;67:159-165.

17. Rodrigue JR, Baz MA, Kanasky WF Jr, MacNaughton KL. Does lung transplantation improve health-related quality of life? The University of Florida experience. J Heart Lung Transplant. 2005;24:755-763.

18. Gerbase MW, Spiliopoulos A, Rochat T, Archinard M, Nicod LP. Health-related quality of life following single or bilateral lung transplantation: a 7-year comparison to functional outcome. Chest. 2005; 128:1371-1378.

19. Swigris JJ, Gould MK, Wilson SR. Health-related quality of life among patients with idiopathic pulmonary fibrosis. Thorax. 2005;60: 588-594.

20. Singer LG, Gould MK, Glidden DV, Theodore J. Effect of lung transplantation on quality-adjusted survival in emphysema. J Heart Lung Transplant. 2002;21:154.

21. Yusen RD, Brown KL, Habrock TE, et al. The impact of lung transplantation on quality of life in patients with COPD. J Heart Lung Transplant. 2005;24:S156-S157.

22. Stavem K, Bjortuft O, Borgan O, Geiran O, Boe J. Lung transplantation in patients with chronic obstructive pulmonary disease in a national cohort is without obvious survival benefit. J Heart Lung Transplant. 2006;25(1):75-84.

23. Limbos MM, Chan CK, Kesten S. Quality of life in female lung transplant candidates and recipients. Chest. 1997;112:1165-1174.

24. Rodrigue JR, Baz MA. Are there sex differences in health-related quality of life after lung transplantation for chronic obstructive pulmonary disease? J Heart Lung Transplant. 2006;25:120-125.

25. Lanuza DM, McCabe M, Norton-Rosko M, Corliss JW, Garrity E. Symptoms experiences of lung transplant recipients: comparisons across gender, pretransplantation diagnosis, and type of transplantation. Heart Lung. 1999;28:429-437.

26. Nickels MW. Common psychiatric problems in the well transplant patient. Graft. 2001;4:290-298.

27. van Den Berg JW, Geertsma A, van der Bij W, et al. Broncholitis obliterans syndrome after lung transplantation and health-related quality of life. Am J Respir Crit Care Med. 2000;161:1937-1941.

28. Vermeulen KM, Ouwens JP, van der Bij W, Koëter GH, TenVergert EM. Long term quality of life in patient surviving at least 55 months after lung transplantation. Gen Hosp Psychiatry. 2003;25:95-102.

29. Vasiliadis HM, Collet JP, Poirier C. Health-related quality-of-life determinants in lung transplantation. J Heart Lung Transplant. 2006;25(2):226-233.

30. MacNaughton KL, Rodrigue JR, Cicale M, Staples EM. Health-related quality of life and symptom frequency before and after lung transplantation. Clin Transplant. 1998;12(4):320-323.

31. Snyder LD, Palmer SM. Quality, quantity, or both? Life after lung transplantation. Chest. 2005;128(3):1086-1087.

32. Santana MJ, Feeny D, Johnson JA. Assessing the use of health-related quality of life measures in routine clinical care of lung-transplant patients. Qual Life Res. 2010;19(3):371-379.

33. Yusen RD. Technology and outcomes assessment in lung transplantation. Proc Am Thorac Soc. 2009;16:128-136.

The manuscript management system is completely online and includes a very quick and fair peer-review system. Visit http://www.dovepress. com/testimonials.php to read real quotes from published authors. 